\title{
Associations between parental ideology and neural sensitivity to cognitive conflict in children
}

\author{
Tracy A. Dennis ${ }^{1}$, David M. Amodio ${ }^{2}$, and Laura J. O'Toole ${ }^{1}$ \\ ${ }^{1}$ Department of Psychology, Hunter College, The City University of New York, New York, NY, USA \\ ${ }^{2}$ Department of Psychology, New York University, New York, NY, USA
}

\begin{abstract}
Processes through which parental ideology is transmitted to children-especially at a young age prior to the formation of political beliefs - remain poorly understood. Given recent evidence that political ideology is associated with neural responses to cognitive conflict in adults, we tested the exploratory hypothesis that children's neurocognitive responses to conflict may also differ depending on their parents' ideology. We assessed relations between parental political ideology and children's neurocognitive responses to conflict, as measured by the N2 component of the event-related potential. Children aged 5-7 completed an age-appropriate flanker task while electroencephalography was recorded, and the N2 was scored to incongruent versus congruent flankers to index conflict processing. Because previous research documents heightened liberal-conservative differences in threatrelevant contexts, each trial of the task was preceded by an angry face (threat-relevant) or comparison face (happy or neutral). An effect of parental ideology on the conflict-related N2 emerged in the threat condition, such that the N2 was larger among children of liberals compared with children of moderates and conservatives. These findings suggest that individual differences in neurocognitive responses to conflict, heightened in the context of threat, may reflect a more general pattern of individual differences that, in adults, relates to political ideology.
\end{abstract}

Keywords: Political ideology; Conflict monitoring; Conflict sensitivity; N2; Children.

\section{EFFECTS OF PARENTAL IDEOLOGY ON NEURAL SENSITIVITY TO COGNITIVE CONFLICT IN CHILDREN}

As political ideologies become increasingly polarized, the differences between liberals and conservatives are often thought to extend beyond policy preferences to fundamental differences in psychological function. Although a growing body of evidence has linked differences in political views to more general forms of psychological and neural processing, the important question of whether these effects are due to political beliefs, as opposed to dispositions already in place prior to the development of political beliefs, remains unanswered (Hibbing, Smith, \& Alford, 2014; Jost \& Amodio, 2012).
In the current study, we took a developmental approach to exploring this issue by examining a pattern of neurocognitive function, previously associated with political ideology in adults, in the children of liberals, moderates, and conservatives. We reasoned that while these children were unlikely to have refined political beliefs, they would share more basic psychological propensities of their parents (Olson, Vernon, Harris, \& Jang, 2001). If a similar pattern of neurocognitive response was observed in the children of liberals versus conservatives, then this evidence would weigh against the possibility that previously observed ideology effects were due to political beliefs, per se. Furthermore, this observation would provide support for the idea that psychological patterns associated with political

Correspondence should be addressed to: Tracy Dennis, Department of Psychology, Hunter College, The City University of New York, NY, USA. E-mail: tracy.dennis@hunter.cuny.edu 
ideology in adults emerge from cognitive styles already in place at a younger age.

Psychologists have long associated political beliefs with broader cognitive, motivational, and personality styles (Adorno, Frenkel-Brunswik, Levinson, \& Sanford, 1950). More recently, Jost, Glaser, Kruglanski, and Sulloway (2003) proposed that certain ideological positions - such as advocacy versus resistance to social change and rejection versus acceptance of inequality - are adopted in part because they serve more general motivations to reduce uncertainty, ambiguity, and threat. For example, a growing body of research suggests that liberals exhibit a greater tolerance of ambiguity, uncertainty, and complexity, whereas conservatives exhibit less cognitive flexibility and more structured and persistent approaches to decision-making (Jost et al., 2003), as well as less openness to new experiences (Carney, Jost, Gosling, \& Potter, 2008; Gerber, Huber, Doherty, Dowling, \& Ha, 2010). These patterns imply that political ideology may emerge from a broader set of psychological processes, in particular those involved in motivation and self-regulation (Jost \& Amodio, 2012).

Research on the neurocognitive correlates of ideology have focused on individual differences in the processing of conflict - a core component of self-regulation (e.g., Amodio, Jost, Master, \& Yee, 2007; Kanai, Feilden, Firth, \& Rees, 2011; Weissflog, Choma, Dywan, Van Noordt, \& Segalowitz, 2013). Broadly speaking, conflict processing involves the detection of discrepancies-when two or more incompatible response options are activated simultaneously - and the recruitment of neural resources to resolve conflicting or complex information (Barch, Braver, Sabb, \& Noll, 2000; Botvinick, Braver, Barch, Carter, \& Cohen, 2001). This mechanism of cognitive control supports the self-regulation of behavior in the face of complex response options in order to facilitate higher-order goals and intentions.

Conflict processing has been associated with a scalp-recorded event-related potential (ERP), the N2. The N2 occurs over the frontal-midline region beginning approximately 200 to $350 \mathrm{~ms}$ following stimulus onset. Importantly, the amplitude of the N2 is larger to stimuli that evoke a response conflict, such as the presentation of incongruent response options (e.g., incongruent flanker displays in a visual flanker task) or tasks that require the inhibition of prepotent responses, such as No-Go trials in a Go/No-Go task (Kopp, Rist, \& Mattler, 1996; Nieuwenhuis, Yeung, Van Den Wildenberg, \& Ridderinkhof, 2003; Van Veen \& Carter, 2002a). Source analyses suggest that the $\mathrm{N} 2$ is generated by the anterior cingulate cortex (ACC) under circumstances that elicit conflicting response tendencies (Banich et al., 2001; Carter et al., 1998; Van Veen \& Carter, 2002b). The N2 amplitude is therefore believed to indicate the extent to which conflict-related cognitive processes are engaged during tasks.

If political liberals exhibit greater awareness of and responsiveness to complex and potentially conflicting pieces of information, in comparison with conservatives, this difference should be associated with increased ACC activity and its corresponding N2 amplitude. Amodio et al. (2007) investigated this hypothesis in a sample of young adults. After participants indicated their political orientation, they completed a Go/No-Go task in which a small proportion of trials required them to withhold the habitual "Go" response. Amodio et al. (2007) observed that liberals exhibited greater accuracy and larger N2 amplitudes on No-Go trials, in comparison with conservatives. This result was consistent with the hypothesis that liberalism is associated with greater neurocognitive activity under conditions of response conflict. These findings have been conceptually replicated and extended in other studies (Inzlicht, McGregor, Hirsh, \& Nash, 2009; Shook \& Fazio, 2009; Weissflog et al., 2013). Taken in conjunction, this work suggests that the endorsement of a more liberal ideology is associated with enhanced responsiveness of neural systems to cognitive conflict. Given this past evidence, and given prior evidence that individual differences in conflict processing have a significant heritable component (e.g., Matthews et al., 2007), we hypothesized that children of more liberal parents would exhibit larger N2 amplitudes during a conflict monitoring task.

Ideological differences in conflict processing might also be moderated by the emotional context in which cognitive processes operate (McLean et al., 2013). The past decade has seen an explosion of research demonstrating that individual differences, such as enhanced sensitivity to negative and threat-related stimuli, moderate the impact of emotional factors on cognition (e.g., Dennis \& Chen, 2007; Hofmann, Ellard, \& Siegle, 2012; Ohrmann et al., 2007). For individuals showing this enhanced sensitivity, threatrelevant stimuli such as human faces displaying fear and anger can disrupt neurocognitive processes, especially when the threatening stimuli are distracting or irrelevant to task performance (Fox, Russo, \& Dutton, 2002; Mogg, Philippot, \& Bradley, 2004). For example, Dennis and Chen (2009) found that moderately anxious adults, who are thought to show elevated threat sensitivity, evidenced reduced sensitivity of the N2 to incongruent versus congruent flankers following the presentation of task-irrelevant fearful faces. 
Political conservatism is associated with greater sensitivity to negative stimuli (Carraro, Castelli, Macchiella, \& Avenanti, 2011; Jost et al., 2007; Oxley et al., 2008; Shook \& Clay, 2011) and greater vigilance for potential threats in the environment (Dodd, Balzer, \& Jacobs, 2012; McLean et al., 2013). For instance, conservatives are more likely than liberals to respond to negative or threatening images with increased physiological arousal and to rapidly fixate upon the images, suggesting increased cognitive resources devoted to threat (Dodd et al., 2012; Hibbing et al., 2014). Thus, it is possible that threat-related contexts may amplify neurocognitive differences between liberals and conservatives, whereas pleasant or neutral contexts would not. Consistent with this notion, McLean et al. (2013) found that conservatives, but not liberals, displayed enhanced sensitivity to angry targets, measured by reaction times indexing greater attentional focusing.

In the present study, we varied the emotional context of conflict monitoring by displaying an angry face (threat-relevant) or a comparison face (happy or neutral) prior to each trial of a flanker task. These faces were task-irrelevant because they provided no information about the target flanker task. We considered the possibility that liberal-conservative individual differences in the N2 response to conflict (greater N2 amplitudes to incongruent flankers among children of liberals versus conservatives) would be heightened in the threat-relevant context. This follows from the idea that children of liberals, relative to conservatives, would be less reactive to the task-irrelevant angry faces and thus more able to cognitively engage with the target flanker task.

The goal of the present study was to test whether enhanced neurocognitive responses to conflict, which has been observed in more liberal versus conservative adults (e.g., Amodio et al., 2007), are exhibited by children of liberals, as compared to children of conservatives. We recruited early school-aged children (ages 5-7) and obtained parents' reports of their own political orientation. Child participants then completed the Attention Network Test (ANT) while electroencephalography (EEG) was recorded to generate the N2. The ANT is a cued version of the Eriksen flanker task, which has been shown to elicit ACC activity and can be used to measure attentional processing in response to congruent and incongruent responses options (Fan, Wu, Fossella, \& Posner, 2001). Moreover, the flanker task has been identified as an especially promising measurement tool for identifying core cognitive processes associated with ideological differences, especially in emotional contexts (McLean et al., 2013). In the present study, we used the ANT to estimate the influence of parental political orientation on both N2 amplitudes and attention performance under conditions of high conflict (incongruent flankers) and low conflict (congruent flankers). A manipulation of emotional context was introduced so that every trial was preceded by the presentation of an angry, pleasant, or neutral face (see Dennis, Malone, \& Chen, 2009). We chose human faces because of their salience and social significance (Johnson, 2005) and compared the effects of angry faces to pleasant and neutral faces to explore whether the effects of parental ideology on conflict monitoring would be strengthened in a threat-relevant emotional context.

Our focal hypothesis was that children of more liberal, as opposed to more conservative, parents would exhibit larger N2 amplitudes, indicating enhanced recruitment of cognitive resources to track and resolve conflict on incongruent trials. In addition, we tested the exploratory hypothesis that these individual differences linked to parental ideology would be stronger when participants were exposed to angry (threat-relevant) faces as compared with happy and neutral faces.

\section{METHOD}

\section{Participants}

Fifty-one children aged 5 to 7 years old $(M=75.33$ months, $S D=6.29$ ) from the New York City area completed the study. Of these 51 children, 8 were excluded because of EEG artifacts produced by excessive movement (on $60 \%$ of trials or more). These eight children were all 5 years old, which is consistent with the fact that younger children have more difficulty remaining still during EEG recording (Banaschewski \& Brandeis, 2007). Ten children were excluded because of excessive response errors or outlying scores with respect to response latencies (more than three standard deviations above the mean), yielding a final sample of 33 participants. Biological parents (30 mothers and 3 fathers) and children were ethnically diverse: $42 \%(n=14)$ were White/ Caucasian; $36 \%(n=12)$ were Black or AfricanAmerican; $12 \%(n=4)$ were Hispanic/Latino; 3\% $(n=1)$ were Asian; and $6 \%(n=2)$ were biracial (i.e., they chose Hispanic and another category). The education level of parents was: $6 \%$ completed 11 th grade $(n=2) ; 3 \%$ completed 12 th grade with no diploma $(n=1) ; 15 \%$ were high school graduates $(n=5) ; 15 \%$ completed some college but did not have a degree $(n=5) ; 24 \%$ had an associate's degree $(n=8) ; 18 \%$ had a bachelor's degree $(n=6) ; 15 \%$ had 
a master's degree $(n=5)$; and 3\% had professional degree $(n=1)$. Median annual household income (before taxes) was "between $\$ 40,000-50,000$ " with a sample range from " $\$ 10,000-\$ 20,000$ " to " $\$ 150,000$ and above." The relationship status of parents was $64 \%$ married $(n=21), 6 \%(n=2)$ unmarried but living with a partner, 9\% $(n=3)$ separated, 3\% $(n=1)$ divorced, and $18 \%(n=6)$ never married. Eighty-five percent of the children were righthanded $(n=28)$.

\section{Procedures}

Prior to beginning the EEG portion of the experiment, informed consent was obtained from parents and children. All consented to participation. The entire laboratory visit lasted approximately 2.5 hours, and children were informed that they could take a break any time.

\section{Attention network test}

EEG was recorded while children completed a modified version of the Child Attention Network Test (ANT; Dennis et al., 2009; Rueda et al., 2004) in the experimental booth. Participants were seated approximately $65 \mathrm{~cm}$ from a personal IBM computer with a 14-inch monitor (Windows XP) in a dimly lit room. The ANT, which was presented using E-Prime software (Psychological Software Tools, Pittsburgh, PA), involves a combination of cued reaction time (Posner, 1980) and a flanker task. In the flanker task, participants must respond to a central target stimulus, such as an arrow, that points toward either the left or right side of the screen. Participants are instructed to press a button to indicate the direction of the arrow (left or right). However, the target stimulus is flanked by additional stimuli on both sides. On some trials, the flanker stimuli point in the same direction of the target; hence, these trials are referred to as "congruent" flankers. On other trials, the flankers point toward the opposite direction and are thus referred to as "incongruent." Comparing responses to incongruent versus congruent flankers provides a measure of conflict monitoring.

The original ANT designed for adults used arrows to represent the focal stimuli and flankers (Fan, McCandliss, Sommer, Raz, \& Posner, 2002). To make the task more relevant and interesting to young children, the target (central) and flanking stimuli (two on each side) were changed to fish (Rueda et al., 2004). Children were instructed to "catch the fish named Fun" in the center of the screen by indicating the direction in which the fish's nose was pointing (selecting the right or left mouse button as quickly as they could). Targets with fish all pointing in the same direction are congruent and those with the central fish pointing in a different direction than the flanking fish are incongruent. There were equal numbers of congruent and incongruent trials. Children were given a six-trial practice block before starting the three experimental blocks and were given feedback on their performance. Between blocks, children were given short breaks in which to rest.

Trials were preceded by cueing conditions that served to alert the child to the impending target or to orient children to a location on the screen where the target will appear. These cueing conditions can also be used to calculate performance efficiency scores in multiple domains of attention (alerting, orienting, and executive). However, because the present study's hypotheses focused on speed and accuracy under conditions of high versus low conflict (incongruent versus congruent flankers), reaction times were collapsed across cueing conditions, separately by flanker type.

Based on previous studies (Dennis \& Chen, 2009; Dennis et al., 2009), the task was modified by briefly presenting angry, happy, or neutral faces for $200 \mathrm{~ms}$ prior to each trial to determine the extent to which threat-relevant (versus pleasant or neutral) stimuli influence N2 amplitudes and attentional performance. Participants were presented with three experimental blocks, with each block presenting angry, happy, or neutral faces prior to each trial. Order of blocks was counterbalanced across participants. Each block included 64 trials, which were equally divided between congruent and incongruent flanker displays. There were 48 grayscale photographs of faces, and these were equally divided, so there were 16 from each of the three categories of facial expression (Tottenham et al., 2009).

Each trial consisted of a series of events (see Figure 1). First, an emotional face stimulus (angry, happy, or neutral) was presented for $200 \mathrm{~ms}$, followed by a fixation cross, which was variably presented on the screen for 400-1600 ms. Subsequently, one of the four cueing conditions (no cue, center cue, double cue, or spatial cue) was presented for $150 \mathrm{~ms}$. This was again followed by the fixation cross that was presented for $450 \mathrm{~ms}$. After the fixation period, the central target (along with the flankers pointing in either congruent or incongruent directions in comparison to the central target) was displayed for up to $1700 \mathrm{~ms}$ or until a response was made. The flanker display disappeared when the button was pressed. The final event consisted of a fixation period that was variably presented for $1000 \mathrm{~ms}$. No feedback on performance was given. Each trial lasted for a maximum of $5100 \mathrm{~ms}$. Prior to averaging reaction 


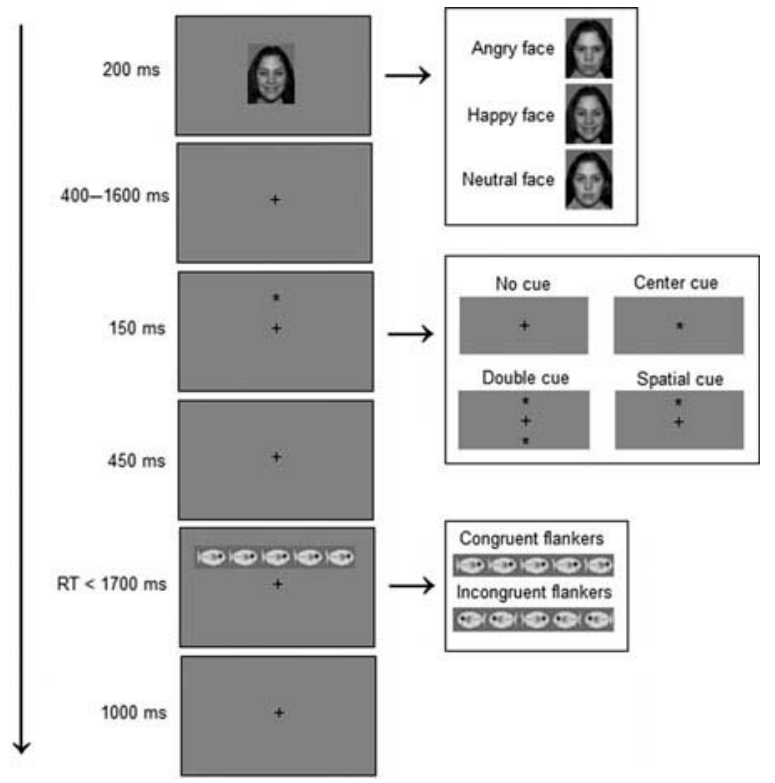

Figure 1. Experimental procedure for the modified ANT (see also Dennis et al., 2009). Participants indicate the direction in which the nose of the fish in the center of the target display is pointing. Targets with fish all pointing in the same direction are congruent and those with the central fish pointing in a different direction than the flanking fish are incongruent.

times (RTs) for each stimulus condition, trials with outliers (RTs \pm 3 standard deviations from each participant's mean) were discarded. RT and error rates to congruent and incongruent flankers were the target measures of interest.

\section{EEG recording}

Using the BioSemi system (BioSemi, Amsterdam, NL), EEG activity was recorded continuously via 64 $\mathrm{Ag} / \mathrm{AgCl}$ scalp electrodes embedded in an elasticized nylon cap based on the international 10/20 system. Eye movements were monitored by electrooculogram (EOG) from electrodes placed $1 \mathrm{~cm}$ above and below the left eye (to measure vertical eye movements) and $1 \mathrm{~cm}$ on the outer corner of each eye (to measure horizontal eye movements). The EEG signal was preamplified at the electrode to improve the signal-tonoise ratio. EEG was recorded at a sampling rate of $512 \mathrm{~Hz}$. The voltage from each active electrode was referenced online with respect to a common mode sense active electrode producing a monopolar (nondifferential) channel.

Offline data processing was conducted using Brain Vision Analyzer (Version 2.2, GmbH, Munich, DE).
Data were re-referenced offline to an average reference and filtered with a high pass frequency of $.1 \mathrm{~Hz}$ and a low pass frequency of $30 \mathrm{~Hz}$. The EEG was segmented for each trial beginning $400 \mathrm{~ms}$ prior to flanker onset and continuing for $800 \mathrm{~ms}$. Baseline correction was performed for each trial, using the $200 \mathrm{~ms}$ prior to flanker onset.

EEG was corrected for blinks using independent components analysis (ICA). Artifacts were identified using the following criteria: any data with voltage steps exceeding $75 \mu \mathrm{V}$, changes within a segment that were greater than $200 \mu \mathrm{V}$, amplitude differences greater than $\pm 120 \mu \mathrm{V}$ within a segment, and activity lower than $.2 \mu \mathrm{V}$ per $100 \mathrm{~ms}$. Such artifacts were excluded from analysis. After ICA, data were visually inspected to confirm successful eyeblink removal and to detect any remaining artifacts. Data from individual channels containing artifacts were rejected on a trial-by-trial basis.

Prior to analyses, outliers were removed from raw RT and N2 data using a 90\% Winsorization: data falling below the 5 th percentile were set to the value of the 5th percentile and data falling above the 95th percentile were set to the 95th percentile. Analyses targeted the conflict-related N2 component, which was found by Amodio et al. (2007) to be associated with political ideology in adults. The N2 was quantified for correct trials only as the peak amplitude between $300-370 \mathrm{~ms}$ post-stimulus onset to the flankers at electrode Fz, where N2 amplitudes were

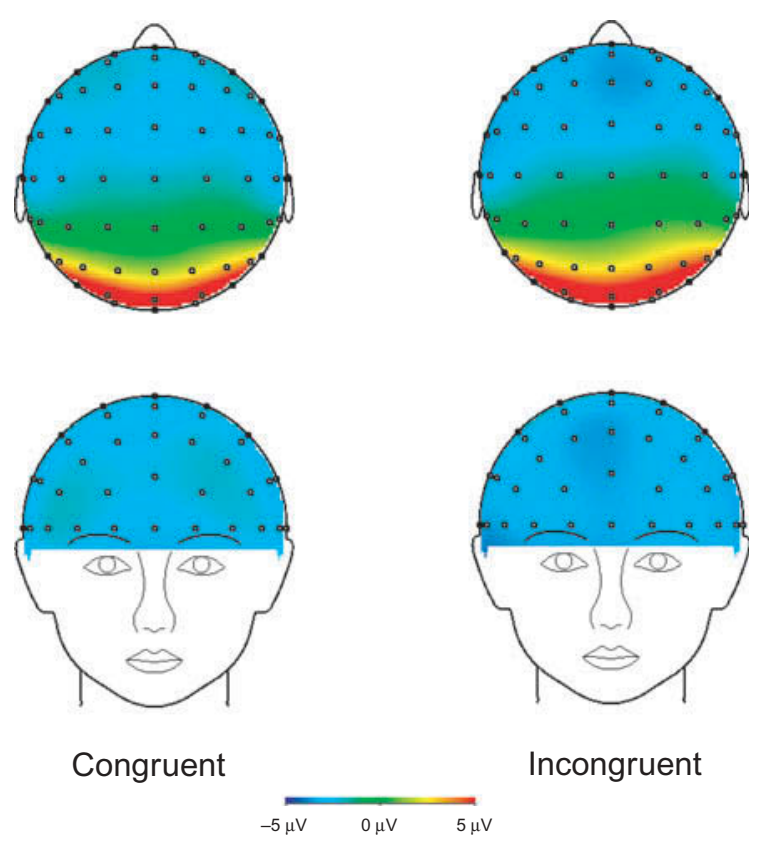

Figure 2. Scalp distribution of the N2 for incongruent and congruent flankers, averaged across the three emotion conditions. 
TABLE 1

Means and standard deviations for N2 amplitudes and attention performance on the attention network test following each emotional face condition

\begin{tabular}{lcccc}
\hline & Angry faces & Happy faces & Neutral faces & Average \\
\hline N2 amplitudes (mean mV) & & & & $-6.52(3.98)$ \\
$\quad$ Incongruent & $-7.07(4.70)$ & $-6.89(4.74)$ & $-5.60(5.55)$ & $-5.05(3.70)$ \\
$\quad$ Congruent & $-4.75(5.39)$ & $-5.08(4.31)$ & $-5.31(5.53)$ & $0.32(0.19)$ \\
Error rate (\%) & & & & $0.34(0.22)$ \\
$\quad$ Incongruent & $0.32(0.21)$ & $0.31(0.20)$ & $0.23(0.20)$ & $0.22(0.17)$ \\
$\quad$ Congruent & $0.22(0.19)$ & $912.22(166.28)$ & $905.99(188.6)$ & $912.08(154.28)$ \\
Reaction time (in ms) & $918.03(159.76)$ & $847.46(148.52)$ & $851.47(172.13)$ & $851.18(144.17)$ \\
$\quad$ Incongruent & $854.61(155.26)$ & &
\end{tabular}

Notes: Means are presented with standard deviations in parentheses. N2 amplitudes and reaction times are based on correct trials only.

maximal. All participants showed their maximal amplitude within this window. Figure 2 illustrates the scalp distribution of the N2 for incongruent and congruent flankers, separately. Peak amplitudes were calculated for each flanker type, separately for each face condition (angry, happy, neutral). In addition, N2 difference scores were calculated as the difference between incongruent and congruent flankers following each face type. This difference score was used as an indicator of neural sensitivity to stimulus-response conflict. The average number of trials used to calculate the N2 for incongruent flankers was 20.41 $(S D=6.09)$ and for congruent flankers was 23.63 $(S D=5.67)$.

\section{Questionnaires}

\section{Parental ideology}

To assess political orientation (or ideology), we asked parents to place themselves on a scale ranging from -5 (Extremely Liberal) to 5 (Extremely Conservative). A response of zero was described as "neither liberal nor conservative" and for the present study was considered to indicate moderate (i.e., centrist) political views. This single item strongly predicts presidential voting intentions and a number of other social and political attitudes and behaviors (Jost, 2006). Parental ideology was examined as a continuous variable and also in terms of liberal, moderate, and conservative groups, so that negative scores were coded as liberal, scores of zero as moderate, and positive scores as conservative. Using this scoring system, roughly three equal groups emerged: liberal $(n=12)$, moderate $(n=9)$, and conservative $(n=12)$. The mean score for all parents on this scale was -0.15 $(S D=2.31)$ with a wide range of scores from -4 to 5 .

\section{RESULTS}

\section{Descriptive statistics}

Descriptive statistics concerning children's task performance and N2 amplitudes are presented in Table 1. Mean values are shown separately by flanker type (incongruent or congruent) and whether the trial was preceded by angry, happy, or neutral faces. Figure 3 shows N2 amplitudes for congruent and incongruent trials for children of conservative, moderate, and liberal parents separately for each face condition. Children's age was unrelated to parental political orientation: for conservative parents, $M$ age in months $=75.92(S D=4.54)$, for moderate parents, $M=75.44(S D=6.15)$, and for liberal parents, $M=74.67(S D=8.14)$.

\section{Correlations among study variables}

Bivariate correlations were computed for all study variables to determine whether parental ideology was associated with conflict-related neurocognitive functioning ( $\mathrm{N} 2$ amplitudes to incongruent trials) and attentional performance (RTs and error rates on incongruent trials) for a total of nine correlations. ${ }^{1}$ Consistent with predictions, greater parental liberalism (lower scores on ideology) was associated with larger $\mathrm{N} 2$ amplitudes following angry faces, $r(33)=.39, p=.03$ (see Figure 4). No other significant correlations between parental ideology and N2 amplitudes emerged, and no other correlations among study variables reached significance.

\footnotetext{
${ }^{1}$ When race/ethnicity and education were entered as covariates, the results remained the same.
} 

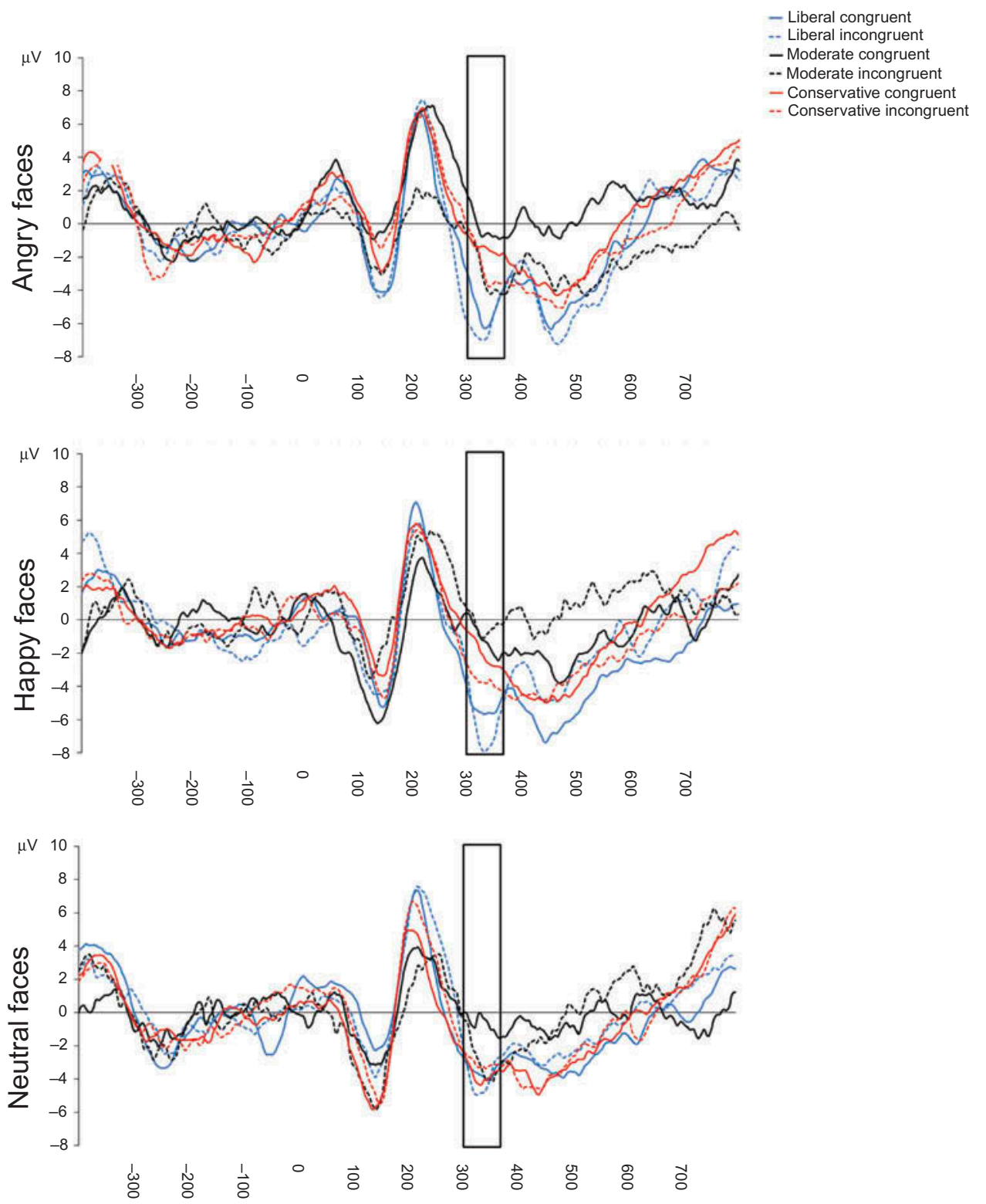

Figure 3. N2 amplitudes for congruent and incongruent trials for the children of liberals, moderates, and conservatives separately for each face condition.

\section{Associations between parental ideology and child attentional performance}

We explored whether children of liberals, as compared with those of conservatives, would exhibit performance differences on high conflict (incongruent) stimulus trials, as a function of emotional context. Reaction time and error rate scores were submitted separately to 3 (parental ideology: liberal, moderate, conservative) $\times 2$ (flanker: incongruent, congruent $) \times 3$ (emotion: angry, happy, neutral) repeated measures ANOVAs.
Main effects of flanker congruence emerged for each dependent variable, indicating that, unsurprisingly, performance on the ANT was poorer under conditions of response conflict. Specifically, the analysis of error rates yielded a main effect of flanker $[F(1,30)=23.47$, $\left.p=.001 \eta^{2}=.44\right]$ indicating that errors were greater for incongruent $[M=0.33 \pm 0.06]$ than congruent flankers $[M=0.22 \pm 0.06, p=.001]$, as did the analysis of reaction times $\left[F(1,30)=43.92, p=.001 \eta^{2}=.59\right]$ indicating that reaction times were longer for incongruent $[M=915 \pm 54]$ than congruent flankers $[M=855 \pm 50, p=.001]$. 


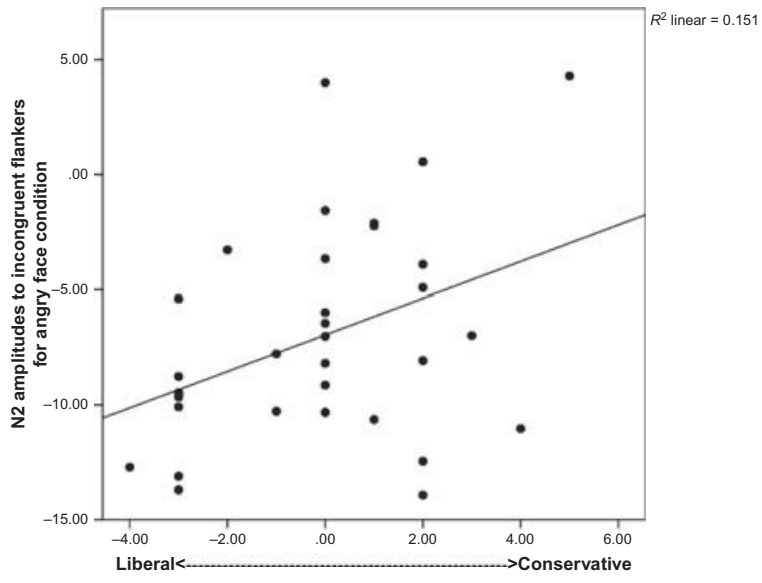

Figure 4. Children of more liberal parents showed greater N2 amplitudes to incongruent flankers following angry faces.

Additionally, the emotion $\times$ parental ideology interaction was significant for reaction times $[F(4,60)=2.72$, $\left.p=.04, \eta^{2}=.15\right]$ indicating that children of conservatives had faster reaction times following neutral faces, regardless of flanker type $[M=880 \pm 90]$, than children of moderates $[M=970 \pm 102, p=.04]$. Among children of conservatives only, reaction times were faster following neutral versus angry faces $[M=880 \pm 90, p=.03]$.

\section{Associations between parental ideology and child N2 amplitudes}

To investigate our focal prediction that the conflictrelated N2 amplitudes would be larger among children with more politically liberal parents, we conducted a 3 (parental ideology: liberal, moderate, conservative) $\times 2$ (flanker: incongruent, congruent) $\times 3$ (emotional expression: angry, happy, neutral) repeated measures ANOVA. This analysis tested the prediction that ideological differences would be greater under conditions of threat (i.e., following exposure to angry faces) relative to nonthreat (happy or neutral faces). It also enabled us to explore whether children of political moderates would exhibit patterns of response that more closely resembled those of liberals or conservatives.

The ANOVA yielded a significant main effect of flanker $\left[F(1,30)=7.74, p=.009, \eta^{2}=.21\right]$ indicating that $\mathrm{N} 2$ amplitudes were greater to incongruent $[M=-6.47 \pm 1.39]$ versus congruent flankers $[M=-4.95 \pm 1.20, p=.009]$. Additionally, the parental ideology $\times$ emotion interaction reached significance, $F(4,60)=2.76, p=.04, \eta^{2}=.16$ (see Figure 5$)$. Simple effects analyses revealed that in the angry face condition children of liberals $[M=-8.66 \pm 2.26]$

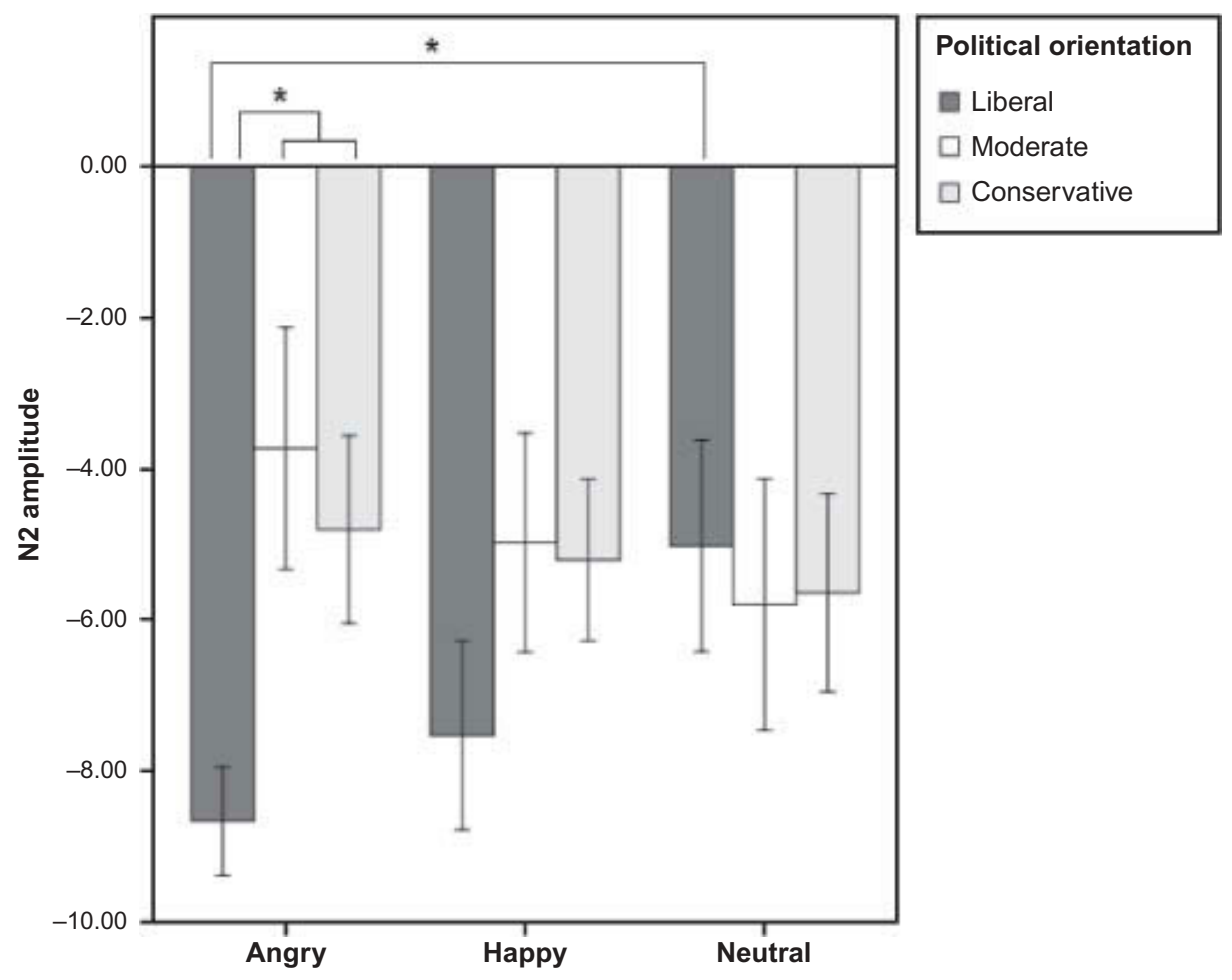

Figure 5. Interaction between parental ideology and emotion type for N2 amplitudes. Errors bars show \pm 1 standard error. ${ }^{*} p<.05$. 
exhibited significantly larger N2 amplitudes than both children of moderates $[M=-3.73 \pm 2.60, p=.008]$ and children of conservatives $[M=-4.80 \pm 2.26$, $p=.02]$. Furthermore, children of liberals exhibited significantly larger N2 amplitudes in the angry versus neutral $[M=-5.02 \pm 2.76, p=.01]$ face conditions. ${ }^{2}$

\section{DISCUSSION}

As evidence for the neurocognitive correlates of political ideology builds, researchers are increasingly faced with the questions of whether these correlates relate to political views per se or whether they reflect a more general cognitive style that likely developed earlier in life (e.g., Block \& Block, 2006). Findings from the current study raise the possibility that neurocognitive responses to conflict - a form of processing that has been associated with ideology in multiple studiesreflect a more general pattern of individual differences present in childhood that relates, later in adulthood, to political ideology. Specifically, children of liberal parents exhibited larger N2 amplitudes during both incongruent and congruent trials of a flanker task, indicating enhanced recruitment of cognitive resources to detect and resolve conflict, in comparison with children of moderate and conservative parents. This effect only emerged in trials following threat-relevant angry faces. This pattern conceptually replicates, in children, an effect of ideology on neurocognitive functioning that has been documented in studies involving adults (e.g., Amodio et al., 2007; Shook \& Fazio, 2009; Weissflog et al., 2013), and points to the potential role of the emotional context, in particular that of threat-relevant information. These findings are broadly consistent with the idea that psychological patterns associated with political ideology in adults may emerge from cognitive styles already in place at a younger age, rather than reflecting political beliefs per se.

Predicted effects of parental ideology on the N2 emerged, but were only observed in the presence of threat-relevant stimuli (angry faces), which previous research suggests may elicit reduced reactivity in liberal as compared to conservative adults (Jost et al., 2007; Oxley et al., 2008). The specificity of this effect in the context of negative and threat-relevant stimuli has several implications. Consistent with the view that liberalism is associated with greater ability to integrate and process aversive, complex, or threat-relevant stimuli (Jost et al., 2007; Oxley et al., 2008), it is

\footnotetext{
${ }^{2}$ The pattern of effects was the same with mean N2 amplitudes (calculated as the area under the curve from 300 to $370 \mathrm{~ms}$ ). There were no significant effects for N2 latency when using the peak data.
}

possible that the offspring of liberal adults share this basic individual difference prior to the formation of political beliefs. This would explain the finding that neurocognitive processing of conflict in the children of liberals versus more conservative adults remained relatively robust in the context of stimuli that were task-irrelevant and threatening (in the present study, angry faces). Indeed, previous research suggests that threat sensitivity in childhood predicts ideology in adulthood: rigid and anxious qualities in early childhood predict conservatism in early adulthood (Block $\&$ Block, 2006), and early temperamental fearfulness predicts conservatism in late adolescence (Fraley, Griffin, Belsky, \& Roisman, 2012). This idea that heightened sensitivity to a threat-relevant emotional context is associated with disruptions in the sensitivity of the N2 to conflict is consistent with research showing such disruptions in trait anxious adults (Dennis \& Chen, 2009).

On the other hand, other research suggests that low arousal, threatening stimuli may facilitate cognitive performance in general (Fenske \& Eastwood, 2003; Gable \& Harmon-Jones, 2010; O'Toole, DeCicco, Hong, \& Dennis, 2011). Conflict monitoring, which is rapidly developing during this age period (Jonkman, 2006; Rueda et al., 2004; Rueda, Posner, \& Rothbart, 2005), may have been facilitated in children of liberals because they, like their parents, have greater ability to devote resources to a task despite task-irrelevant and distracting negative stimuli. At the same time, following angry faces, children of liberals showed a greater N2 response to both incongruent and congruent trials, the latter in which reduced N2 amplitudes are expected. An important question for future research is whether this reduced discrimination between distinct levels of conflict represents general increased engagement with the task or other processes, such as increase cognitive vigilance. Overall, the specificity of the effects of parental ideology that we observed on child N2 responses suggests that future research should systematically investigate the emotional contexts in which neurocognitive differences between liberals and conservatives do and do not emerge, as well as the developmental trajectory of these differences. Moreover, it supports the idea that these individual differences in cognitive responses precede the development of discrete political views.

In general, previous studies suggest that liberalism is associated with greater cognitive flexibility and integrative complexity (e.g., Jost et al., 2003). In the present study, however, we observed only one, unexpected, link between parental political orientation and attentional performance in children: children of both liberal and conservative parents 
showed faster reaction times following neutral faces. This effect was unrelated to ERP findings in that the N2 was sensitive to parental ideology only in the context of angry faces. Thus, this reaction time effect may reveal that neutral faces simply interfere less with task performance compared to valenced stimuli (happy and angry faces in this study). Moreover, neurocognitive differences in conflict processing in young children may reflect relatively subtle difference in cognitive function that may not have a direct impact on standard metrics of attention performance during a moderately difficult conflict monitoring task (in this study, errors ranged from around 20-30\%). Thus, this divergent finding of distinct effects of emotion in the behavioral and neurophysiological realm could reflect a developmental sequence in which the N2 is sensitive to early individual differences in neurocognitive responses to threat that are not yet readily apparent in behavior, but which may have a systematic impact on the development of other functional capacities later in life (Banaschewski \& Brandeis, 2007; Burghy et al., 2012). Tracking such epigenetic processes in cognitive responses associated with the emergence of political ideology is a crucial goal for future research.

Although our study provided new data on the role of conflict processing in children as it relates to their parent's ideology, several limitations are notable. For example, parental ideology was assessed using a single-item measure. While this single item has been shown to strongly predict major political behaviors, such as voting decisions (Jost, 2006), it is possible that a multi-dimensional assessment of parental ideology may have revealed additional complexity to the observed relation with children's conflict processing. In addition, the primary task, the modified flanker task, used to generate both the $\mathrm{N} 2$ and measures of attention performance, may have limited our ability to compare our findings with those from other studies on ideology and the N2, which have typically used the Go-/No-Go task (e.g., Amodio et al., 2007).

It is further notable that this study was not designed to examine the process through which political orientation is passed from a parent to a child. Moreover, children aged 5 to 7 years are unlikely to have developed substantial political beliefs (Hess \& Torney, 2005). Rather, this study speaks to the important question of whether concordances between parental ideology and individual differences in children's cognitive responses to conflict are already in place at a young age, prior to the likely development of political beliefs, and thus are not due to political views per se.
The results of the current study suggest that neurocognitive patterns associated with political ideology in adults may emerge from cognitive styles already in place at a younger age.

It is important to stress that neurodevelopmental issues should be taken into account when interpreting results. The sensitivity of the N2 to conflict may not yet be stable in early childhood (Buss, Dennis, Brooker, \& Sippel, 2011) - the target age of the present study. A possible implication of this developmental variability is that the greater $\mathrm{N} 2$ responses in children of liberals (versus moderates and conservatives) might reflect neurodevelopmental maturity rather than responsivity to conflict. Yet, the sample as a whole evidenced an "adult-like" flanker effects (i.e., greater N2 amplitudes to incongruent versus congruent flankers). Group differences specific to the angry face context suggest that children's neurocognitive responses, because they are developing so rapidly, may be especially sensitive to affective contexts. In other words, a threat-related context might have either bolstered the recruitment of cognitive resources in the service of conflict processing among children of liberals or interfered with this capacity in children of moderates and conservatives. Because the amplitude of the $\mathrm{N} 2$ is believed to signal the extent to which cognitive resources are recruited under conditions of conflict, this further shows that a threat-related context has distinct neurocognitive implications for children of liberal versus conservative parents.

In summary, the present study provides the first evidence to our knowledge that individual differences in conflict processing associated with political ideology in adults is present in the young children of liberals, moderates, and conservative - even though these children presumably have not yet developed refined political beliefs. This evidence weighs against the conclusion that previously observed ideology effects on conflict processing in adults were due to political beliefs, per se, and instead suggests that psychological patterns associated with political ideology in adults may emerge from cognitive styles already in place at a younger age. These findings help to lay the groundwork for theoretical and empirical research addressing the origins, development, and cross-generational transmission of political ideology. Such research also has broader implications for the creation of developmental cognitive neuroscience models that identify biomarkers and neural mechanisms in the development of beliefs, values, and opinions.

Original manuscript received 3 December 2013 Revised manuscript accepted 16 September 2014 First published online 15 October 2014 


\section{REFERENCES}

Adorno, T. W., Frenkel-Brunswik, E., Levinson, D. J., \& Sanford, R. N. (1950). The authoritarian personality. New York, NY: Harper.

Amodio, D., Jost, J., Master, S., \& Yee, C. (2007). Neurocognitive correlates of liberalism and conservatism. Nature Neuroscience, 10(10), 1246-1247. doi:10.1038/nn1979

Banaschewski, T., \& Brandeis, D. (2007). Annotation: What electrical brain activity tells us about brain function that other techniques cannot tell us - a child psychiatric perspective. Journal of Child Psychology and Psychiatry, 48(5), 415-435. doi:10.1111/j.1469-7610.2006.01681.x

Banich, M. T., Milham, M. P., Jacobson, B. L., Webb, A., Wszalek, T., Cohen, N. J., \& Kramer, A. F. (2001). Chapter 29 Attentional selection and the processing of task-irrelevant information: Insights from fMRI examinations of the Stroop task. Vision: From Neurons to Cognition, 134, 459-470. doi:10.1016/S0079-6123(01) 34030-X

Barch, D. M., Braver, T. S., Sabb, F. W., \& Noll, D. C. (2000). Anterior cingulate and the monitoring of response conflict: Evidence from an fMRI study of overt verb generation. Journal of Cognitive Neuroscience, 12(2), 298-309. doi:10.1162/089892900562110

Block, J., \& Block, J. H. (2006). Nursery school personality and political orientation two decades later. Journal of Research in Personality, 40(5), 734-749. doi:10.1016/j. jrp.2005.09.005

Botvinick, M. M., Braver, T. S., Barch, D. M., Carter, C. S., \& Cohen, J. D. (2001). Conflict monitoring and cognitive control. Psychological Review, 108(3), 624-652. doi:10.1037/0033-295X.108.3.624

Burghy, C. A., Stodola, D. E., Ruttle, R. P., Molloy, E. K., Armstrong, J. M., Oler, J. A., \& Birn, R. M. (2012). Developmental pathways to amygdala-prefrontal function and internalizing symptoms in adolescence. Nature Neuroscience, 15(12), 1736-1741. doi:10.1038/nn.3257

Buss, K. A., Dennis, T. A., Brooker, R. J., \& Sippel, L. M. (2011). An ERP study of conflict monitoring in 4-8-year old children: Associations with temperament. Developmental Cognitive Neuroscience, 1(2), 131-140. doi:10.1016/j.den.2010.12.003

Carney, D. R., Jost, J. T., Gosling, S. D., \& Potter, J. (2008). The secret lives of liberals and conservatives: Personality profiles, interaction styles, and the things they leave behind. Political Psychology, 29(6), 807-840. doi:10.1111/j.1467-9221.2008.00668.x

Carraro, L., Castelli, L., Macchiella, C., \& Avenanti, A. (2011). The automatic conservative: Ideology-based attentional asymmetries in the processing of valenced information. Plos ONE, 6(11), 1-6. doi:10.1371/journal.pone.0026456

Carter, C., Braver, T., Barch, D., Botvinick, M., Noll, D., \& Cohen, J. (1998). Anterior cingulate cortex, error detection, and the online monitoring of performance. Science, 280(5364), 747-749. doi:10.1126/science.280.5364.747

Dennis, T. A., \& Chen, C. (2007). Neurophysiological mechanisms in the emotional modulation of attention: The interplay between threat sensitivity and attentional control. Biological Psychology, 76, 1-10. doi:10.1016/j. biopsycho.2007.05.001
Dennis, T. A., \& Chen, C. (2009). Trait anxiety and conflict monitoring following threat: An ERP study. Psychophysiology, 46, 122-131. doi:10.1111/j.14698986.2008.00758.x

Dennis, T. A., Malone, M. M., \& Chen, C. (2009). Emotional face processing and emotion regulation in children: An ERP study. Developmental Neuropsychology, 34(1), 85102. doi:10.1080/87565640802564887

Dodd, M. D., Balzer, A. B., \& Jacobs, C. M. (2012). The political left rolls with the good and the political right confronts the bad: Connecting physiology and cognition to preferences. Philosophical Transactions of the Royal Society B: Biological Sciences, 367, 640-649. doi:10.1098/rstb.2011.0268

Fan, J., McCandliss, B. D., Sommer, T., Raz, A., \& Posner, M. I. (2002). Testing the efficiency and independence of attentional networks. Journal of Cognitive Neuroscience, 14(3), 340-347. doi:10.1162/089892902317361886

Fan, J., Wu, Y., Fossella, J. A., \& Posner, M. I. (2001). Assessing the heritability of attentional networks. BMC Neuroscience, 2(1), 14. doi:10.1186/1471-2202-2-14

Fenske, M. J., \& Eastwood, J. D. (2003). Modulation of focused attention by faces expressing emotion: Evidence from flanker tasks. Emotion, 3(4), 327-343. doi:10.1037/ 1528-3542.3.4.327

Fox, E., Russo, R., \& Dutton, K. (2002). Attentional bias for threat: Evidence for delayed disengagement from emotional faces. Cognition and Emotion, 16(3), 355-379. doi:10.1080/02699930143000527

Fraley, R. C., Griffin, B. N., Belsky, J., \& Roisman, G. I. (2012). Developmental antecedents of political ideology: A longitudinal investigation from birth to age 18 years. Psychological Science, 23(11), 1425-1431. doi:10.1177/ 0956797612440102

Gable, P., \& Harmon-Jones, E. (2010). The blues broaden, but the nasty narrows: Attentional consequences of negative affects low and high in motivational intensity. Psychological Review, 21(2), 211-215. doi:10.1177/ 0956797609359622

Gerber, A. S., Huber, G. A., Doherty, D., Dowling, C. M., \& Ha, S. E. (2010). Personality and political attitudes: Relationships across issue domains and political contexts. American Political Science Review, 104, 111133. doi: $10.1017 / \mathrm{S} 0003055410000031$

Hess, R. D., \& Torney, J. (2005). The development of political attitudes in children. Chicago, IL: Aldine Transaction.

Hibbing, J. R., Smith, K. B., \& Alford, J. R. (2014). Differences in negativity bias underlie variations in political ideology. Behavioral and Brain Sciences, 37(3), 297-307. doi:10.1017/S0140525X13001192

Hofmann, S. G., Ellard, K. K., \& Siegle, G. J. (2012). Neurobiological correlates of cognitions in fear and anxiety: A cognitive-neurobiological information-processing model. Cognition and Emotion, 26(2), 282-299. doi:10.1080/02699931.2011.579414

Inzlicht, M., McGregor, I., Hirsh, J. B., \& Nash, K. (2009). Neural markers of religious conviction. Psychological Science, 20(3), 385-392. doi:10.1111/ j.1467-9280.2009.02305.x

Johnson, M. (2005). Subcortical face processing. Nature Reviews, Neuroscience, 6(10), 766-774. doi:10.1038/ nrn1766 
Jonkman, L. M. (2006). The development of preparation, conflict monitoring and inhibition from early childhood to young adulthood: A Go/No-Go ERP study. Brain Research, 1097(1), 181-193. doi:10.1016/j. brainres.2006.04.064

Jost, J. T. (2006). The end of the end of ideology. American Psychologist, 61(7), 651-670. doi:10.1037/0003066X.61.7.651

Jost, J. T., \& Amodio, D. M. (2012). Political ideology as motivated social cognition: Behavioral and neuroscientific evidence. Motivation and Emotion, 36, 55-64. doi:10.1007/s11031-011-9260-7

Jost, J. T., Glaser, J., Kruglanski, A. W., \& Sulloway, F. J. (2003). Exceptions that prove the rule-using a theory of motivated social cognition to account for ideological incongruities and political anomalies: Reply to Greenberg and Jonas (2003). Psychological Bulletin, 129(3), 383-393. doi:10.1037/0033-2909.129.3.383

Jost, J. T., Napier, J. L., Thorisdottir, H., Gosling, S. D., Palfai, T. P., \& Ostafin, B. (2007). Are needs to manage uncertainty and threat associated with political conservatism or ideological extremity? Personality and Social Psychology Bulletin, 33(7), 989-1007. doi:10.1177/ 0146167207301028

Kanai, R., Feilden, T., Firth, C., \& Rees, G. (2011). Political orientations are correlated with brain structure in young adults. Current Biology, 21(8), 677-680. doi:10.1016/j. cub.2011.03.017

Kopp, B., Rist, F., \& Mattler, U. (1996). N200 in the flanker task as a neurobehavioral tool for investigating executive control. Psychophysiology, 33(3), 282-294. doi:10.1111/ j.1469-8986.1996.tb00425.x

Matthews, S. C., Simmons, A. N., Strigo, I., Jang, K., Stein, M. B., \& Paulus, M. P. (2007). Heritability of anterior cingulate response to conflict: An fMRI study in female twins. NeuroImage, 38(1), 223-227. doi:10.1016/j. neuroimage.2007.07.015

McLean, S. P., Garza, J. P., Wiebe, S. A., Dodd, M. D., Smith, K. B., Hibbing, J. R., \& Espy, K. A. (2013). Applying the flanker task to political psychology: A research note. Political Psychology. doi:10.1111/pops. 12056

Mogg, K., Philippot, P., \& Bradley, B. P. (2004). Selective attention to angry faces in clinical social phobia. Journal of Abnormal Psychology, 113(1), 160-165. doi:10.1037/ 0021-843X.113.1.160

Nieuwenhuis, S., Yeung, N., Van Den Wildenberg, W., \& Ridderinkhof, K. R. (2003). Electrophysiological correlates of anterior cingulate function in a go/no-go task: Effects of response conflict and trial type frequency. Cognitive, Affective, \& Behavioral Neuroscience, 3(1), 17-26. doi:10.3758/CABN.3.1.17

O’Toole, L. J., DeCicco, J. M., Hong, M., \& Dennis, T. A. (2011). The impact of task-irrelevant emotional stimuli on attention in three domains. Emotion, 11(6), 13221330. doi: $10.1037 / \mathrm{a} 0024369$
Ohrmann, P., Rauch, A. V., Bauer, J., Kugel, H., Arolt, V., Heindel, W., \& Suslow, T. (2007). Threat sensitivity as assessed by automatic amygdala response to fearful faces predicts speed of visual search for facial expression. Experimental Brain Research, 183, 51-59. doi:10.1007/ s00221-007-1022-0

Olson, J. M., Vernon, P. A., Harris, J. A., \& Jang, K. L. (2001). The heritability of attitudes: A study of twins. Journal of Personality and Social Psychology, 80(6), 845-860. doi:10.1037/0022-3514.80.6.845

Oxley, D. R., Smith, K. B., Alford, J. R., Hibbing, M. V., Miller, J. L., Scalora, M., \& Hibbing, J. R. (2008). Political attitudes vary with physiological traits. Science, 321(5896), 1667-1670. doi:10.1126/ science. 1157627

Posner, M. I. (1980). Orienting of attention. Quarterly Journal of Experimental Psychology, 32, 3-25. doi: $10.1080 / 00335558008248231$

Rueda, M. R., Fan, J., McCandliss, B. D., Halparin, J. D., Gruber, D. B., Lercari, L. P., \& Posner, M. I. (2004). Development of attentional networks in childhood. Neuropsychologia, 42(8), 1029-1040. doi:10.1016/j. neuropsychologia.2003.12.012

Rueda, M. R., Posner, M. I., \& Rothbart, M. K. (2005). The development of executive attention: Contributions to the emergence of self-regulation. Developmental Neuropsychology, 28(2), 573-594. doi:10.1207/ s15326942dn2802_2

Shook, N. J., \& Clay, R. (2011). Valence asymmetry in attitude formation a correlate of political ideology. Social Psychological and Personality Science, 2(6), 650-655. doi:10.1177/1948550611405219

Shook, N. J., \& Fazio, R. H. (2009). Political ideology, exploration of novel stimuli, and attitude formation. Journal of Experimental Social Psychology, 45(4), 995-998. doi:10.1016/j.jesp.2009.04.003

Tottenham, N., Tanaka, J. W., Leon, A. C., McCarry, T., Nurse, M., Hare, T. A., \& Nelson, C. (2009). The NimStim set of facial expressions: Judgments from untrained research participants. Psychiatry Research, 168(3), 242-249. doi:10.1016/j.psychres.2008.05.006

Van Veen, V., \& Carter, C. (2002a). The anterior cingulate cortex as a conflict monitor: FMRI and ERP studies. Physiology \& Behavior, 77(4-5), 477-482. doi:10.1016/S0031-9384(02)00930-7

Van Veen, V., \& Carter, C. (2002b). The timing of actionmonitoring processes in the anterior cingulate cortex. Journal of Cognitive Neuroscience, 14(4), 593-602. doi:10.1162/08989290260045837

Weissflog, M., Choma, B. L., Dywan, J., Van Noordt, S. J. R., \& Segalowitz, S. J. (2013). The political (and physiological) divide: Political orientation, performance monitoring, and the anterior cingulate response. Social Neuroscience, 8(5), 434-447. doi:10.1080/ 17470919.2013.833549 